\title{
ANALISIS KADAR KAFEIN DALAM KOPI BUBUK LOKAL YANG BEREDAR DI KOTA PALU
}

\author{
Analysis of Caffeine Level in Local Coffee Powder that Circulates in Palu City
}

*I Nyoman Suwiyarsa, Siti Nuryanti, dan Baharuddin Hamzah

Pendidikan Kimia/FKIP - Universitas Tadulako, Palu - Indonesia 94118

Received 03 September 2018, Revised 08 October 2018, Accepted 24 November 2018

\begin{abstract}
Analysis of caffeine level in local coffee powder that circulates in Palu city have been done. The purpose of this study was to determine the level of caffeine in local coffee powder, which is engaged in several markets in the city of Palu. Levels of caffeine in the study will be compared with the standard caffeine content according to the SNI 01-35422004 , i.e. $0.45-2 \% \mathrm{w} / \mathrm{w}$. The method used for qualitative analysis was the thin layer chromatography and for quantitative analysis was using $U V$-Vis spectrophotometry. The results of qualitative analysis of six local coffee powders $A, B, C, D, E$, and $F$ showed each a Rf value between 0.32 to 0.40 . Levels of caffeine (per $1 \mathrm{~g}$ of coffee powder) quantitatively ranging from brand samples $A$ to $F$ were $0.83,2.06,1.60,2.63,1.29$, and $1.72 \%$, respectively, percent level of caffeine of six samples of local powdered coffee, samples $A, C, E$ and $F$ in terms of SNI 01-3542-2004 were between $0.45-2.00 \%(w / w)$, while sample $B$ and sample D exceeds $2 \%$ were $2.06 \%$ and $2.63 \%$.
\end{abstract}

Keywords: Coffee Powder, Caffeine, UV-Vis Spectrophotometry

\section{Pendahuluan}

Sulawesi Tengah merupakan salah satu provinsi yang banyak menghasilkan biji kopi, karena di Sulawesi merupakan salah satu sentral tanaman kopi. Kopi yang beredar di Sulawesei Tengah adalah kopi robusta, arabika, liberika dan kopi toraja. Produk kopi yang beredar di Sulawesi Tengah adalah produk kopi kemasan dan non-kemasan. Peredaran produk kopi, meliputi pasar-pasar besar di Sulawesi Tengah, terkhusus pasar-pasar besar di kota Palu antara lain pasar Impres, pasar Masomba dan pasar Biromaru. Kopi yang di jual di pasar-pasar ini adalah kopi yang didatangkan langsung dari tempat tumbuhnya seperti kabupaten Sigi, Poso, Buol dan Toli-toli.

Kopi adalah sejenis minuman yang berasal dari proses pengolahan dan ekstraksi biji tanaman kopi. Saat ini kopi merupakan komoditas nomor dua paling banyak diperdagangkan di dunia setelah minyak bumi, dengan tingkat produksi kopi dunia setidaknya mencapai 7 juta ton per tahun. Kopi merupakan minuman yang paling digemari oleh masyarakat luas, diantaranya Indonesia dari berbagai kalangan dan usia. Saat ini kopi merupakan minuman yang paling banyak di konsumsi setelah air mineral, sehingga kopi memiliki nilai ekonomis yang cukup tinggi (Fatoni, 2015).

Tingginya nilai jual kopi menyebabkan beberapa penjual kopi, menyiasati produk kopi yang dijual dengan mencampurkan kopi dengan bahan pangan lainnya, sehingga akan menekan harga kopi. Adanya pencampur dalam produk kopi akan mempengaruhi rasa dan nilai gizi dari produk kopi tersebut (Ali, dkk., 2012).

\section{${ }^{*}$ Correspondence:}

I Nyoman Suwiyarsa

Program Studi Pendidikan Kimia, Fakultas Keguruan dan Ilmu Pendidikan, Universitas Tadulako

e-mail: nyomansuwiyarsa@gmail.com

Published by Universitas Tadulako 2018
Kopi memiliki banyak manfaat bagi kesehatan, akan tetapi masalah yang dihadapi bagi penikmat kopi adalah kadar kafein yang terkandung di dalamnya. Kafein adalah senyawa alkaloid turunan xanthine (basa purin) yang secara alami banyak terdapat pada kopi. Kafein memiliki efek farmakologis yang bermanfaat secara klinis; seperti menstimulasi susunan syaraf pusat, dengan efek menghilangkan rasa letih, lapar dan mengantuk juga meningkatkan daya konsentrasi dan sebagainya. Namun pada penggunaan kafein secara berlebihan dapat menimbulkan debar jantung, gangguan lambung, tangan gemetar dan lain sebagainya. Kafein yang terkandung pada biji kopi berkisar 1,5\%-2,5\% (Tjay \& Rahadja, 2007).

Kadar kafein dalam kopi yang beredar di pasaran berbeda-beda, karena adanya campuran bahan lainnya. Untuk itu, badan standarisasi nasional (BSN) telah menetapkan standar untuk kadar kafein dalam kopi bubuk berkisar 0,455\%-2\% b/b (SNI 013542-2004), sehingga jika ada kopi yang mengandung kadar kafein yang tinggi perlu dilakukan dekafeinasi, untuk menekan aktivitas kafein di dalam tubuh (Sofiana, 2011).

Penetapan kadar kafein dalam beberapa produk minuman dan bukan minuman, telah banyak dilakukan oleh peneliti sebelumnya dengan berbagai metode, seperti penetapan kadar kafein dalam minuman bersoda jenis kola secara kromatografi cair kerja tinggi (KCKT) (Levita, dkk., 2004). Farida, dkk (2013), meneliti mengenai penurunan kadar kafein dan asam total pada biji kopi Robusta menggunakan teknologi fermentasi anaerob fakultatif dengan mikroba Nopkor MZ-15. Beberapa penelitian tentang kandungan kafein pada kopi menggunakan spektrofotometri UV-Vis (Maramis, dkk., 2013; Aptika, dkk., 2015; Fatoni 2015 dan Arwangga, dkk., 2016). Hasil analisa yang dilakukan oleh peneliti sebelumnya memberikan data analisa yang berbeda. Hal ini dikarenakan, kadar kafein dalam kopi 
dipengaruhi oleh letak geografis dan jenis tanaman kopi.

Tulisan ini dimaksudkan untuk mendeskripsikan kadar kafein dalam kopi bubuk lokal, yang beredar di beberapa pasar di kota Palu. Kadar kafein yang diperoleh dalam penelitian, akan dibandingkan standar kadar kafein menurut SNI 013542-2004 yaitu $0,45-2,00 \% \mathrm{~b} / \mathrm{b}$.

\section{Metode}

Alat yang digunakan dalam penelitian ini adalah spektrofotometri UV-Vis, alat evaporasi, neraca analitik, chamber, beker gelas, labu ukur, corong pisah, kertas saring, lampu UV 254, lampu Bunsen dan peralatan pendukung lainnya. Bahan yang digunakan dalam penelitian ini adalah kafein baku standar, kloroform $\left(\mathrm{CHCl}_{3}\right)$ (Merck), aquades, natrium karbonat $\left(\mathrm{Na}_{2} \mathrm{CO}_{3}\right)$ (Merck) dan sampel kopi bubuk lokal jenis arabika. Sampel kopi A dan B diambil dari pasar Biromaru, sampel kopi C dan D diambil dari pasar Masomba, sedangkan sampel kopi E dan F diambil dari pasar Inpres. Sampel A, C dan E diambil dalam bentuk kopi bubuk, sedangkan sampel kopi B, D dan F dalam bentuk Biji. Sampel kopi A dan B berasal dari kabupaten Sigi, sampel kopi C dan D berasal dari kabupaten Poso, sedangkan sampel kopi E dan F berasal dari kabupaten Buol.

\section{Pembuatan larutan baku standar}

$20 \mathrm{mg}$ standar kafein di masukan ke dalam labu ukur $100 \mathrm{~mL}$, dilarutkan dengan aquades sampai tanda batas dan kocok hingga homogen, dan diperoleh larutan dengan konsentrasi 200 ppm.

\section{Penentuan panjang gelombang serapan maksimum}

$10 \mathrm{~mL}$ larutan induk baku standar ditempatkan ke dalam labu ukur $100 \mathrm{~mL}$, kemudian dilarutkan dengan aquades sampai tanda batas, sehingga diperoleh larutan baku $20 \mathrm{ppm}$. Ukur serapannya, diukur pada panjang gelombang antara $270 \mathrm{~nm}-300 \mathrm{~nm}$.

\section{Penentuan kurva kalibrasi}

Kurva kalibrasi diperoleh dengan membuat serangkain larutan baku standar dengan konsentrasi $0,10,20,30$ dan $40 \mathrm{ppm}$, dengan cara dipipet masing-masing sejumlah $0,5,10,15$ dan $20 \mathrm{~mL}$ ke dalam labu ukur $100 \mathrm{~mL}$, lalu dilarutkan dengan aquades sampai tanda batas. Kemudian di ukur serapannya pada panjang gelombang serapan maksimum dan sebagai blangko digunakan aquades.

\section{Preparasi sampel}

2 gram sampel kopi dimasukan ke dalam gelas dan dilarutkan dengan aquades mendidih sebanyak $100 \mathrm{~mL}$, disaring, lalu filtratnya ditambahkan 2 gram $\mathrm{Na}_{2} \mathrm{CO}_{3}$, kemudian dipanaskan sampai setengah campuran, didinginkan dan dimasukan ke dalam corong pisah. Kemudian diekstraksi dengan kloroform $25 \mathrm{~mL}$ berturut-turut sebanyak empat kali, lalu filtrat ditampung dalam erlemeyer. Kemudian pelarut kloroform diuapkan dengan alat evaporator sehingga didapat ekstrak kafein dalam bentuk cair.
Kafein cair kemudian diuapkan kembali dalam oven sehingga diperoleh kristal kafein. Ekstrak kafein yang dihasilkan selanjutnya dimasukan ke dalam labu ukur $100 \mathrm{~mL}$ dan dilarutkan dengan aquades sampai tanda batas. Kemudian dilakukan pengenceran dengan cara dipipet $2 \mathrm{~mL}$ larutan tersebut ke dalam labu ukur 50 $\mathrm{mL}$ dan dilarutkan dengan aquades sampai tanda batas.

\section{Identifikasi kafein hasil ekstraksi}

Mengambil cuplikan kafein sampel dan kafein baku standar dalam pelarut kloroform. Ditotolkan pada plat $\mathrm{GF}_{254}$, dimasukan kedalam chamber yang telah dijenuhkan dengan fase gerak kloroform-etanol (99:1) (Fatoni, 2015). Kemudian kromatogram dilihat di bawah lampu UV pada panjang gelombang $254 \mathrm{~nm}$.

\section{Penetuan kadar kafein}

Larutan sampel akan diukur serapannya pada panjang gelombang serapan maksimum yang diperoleh yaitu $285 \mathrm{~nm}$, kemudian serapan dicatat. Konsentrasi kafein akan ditentukan berdasarkan persamaan regresi dari kurva kalibrasi standar. Kadar kafein dalam sampel dapat dihitung dengan cara sebagai berikut (Tjay, dkk., 2007):

Kadar kafein $(\mathrm{mg} / \mathrm{g})=(\mathrm{M} . \mathrm{V}$. Fp) / ( m) .

dimana, $\mathrm{M}$ adalah konsentrasi (ppm) atau $(\mathrm{mg} / \mathrm{L}) ; \mathrm{V}$ adalah volume (L); Fp adalah faktor pengenceran dan $\mathrm{m}$ adalah berat sampel $(\mathrm{g})$.

\section{Hasil dan Pembahasan}

\section{Identifikasi kafein hasil ekstraksi}

Ekstraksi adalah suatu cara untuk memisahkan campuran beberapa zat kimia menjadi komponenkomponen yang terpisah. Ekstraksi dengan pelarut dapat dilakukan dengan dua cara, yaitu dengan pelarut air dan dengan pelarut organikIdentifikasi kafein hasil ekstraksi dari kopi bubuk dilakukan dengan membandingkan dengan kafein baku standar dengan cara kromatografi lapis tipis (KLT). Kromatografi lapis tipis adalah salah satu metode pemisahan komponen menggunakan fasa diam berupa plat dengan lapisan bahan adsorben inert. Pengembang yang digunakan adalah kloroform:etanol (v/v : 99:1), jarak pengembang $8 \mathrm{~cm}$. Terlihat noda kafein hasil ekstraksi pada kopi bubuk sejajar dengan baku pembanding dengan nilai $\mathrm{Rf}$ seperti terlihat pada Tabel 1.

Tabel 1. Nilai Rf kafein pada berbagai sampel kopi bubuk lokal

\begin{tabular}{rcc}
\hline Sampel & Rf Sampel & Rf Kafein Baku Standar \\
\hline A & 0,4000 & \\
B & 0,3625 & \\
C & 0,3750 & 0,3375 \\
D & 0,3625 & \\
E & 0,3262 & \\
F & 0,3250 & \\
\hline
\end{tabular}

Nilai Rf sangat karakterisitik untuk senyawa tertentu pada eluen tertentu. Hal tersebut dapat 
digunakan untuk mengidentifikasi adanya perbedaan senyawa dalam sampel. Senyawa yang mempunyai $R f$ lebih besar berarti mempunyai kepolaran yang rendah, begitu juga sebaliknya. Hal tersebut dikarenakan fasa diam bersifat polar. Senyawa yang lebih polar akan tertahan kuat pada fasa diam, sehingga menghasilkan nilai $\mathrm{Rf}$ yang rendah (Maramis, dkk., 2013).

Penggunaan kloroform dan etanol sebagai fasa gerak, karena kloroform dan etanol bersifat polar yang sangat efektif dalam mengidentifikasi senyawa organic. Kloroform dan etanol akan membawa naik senyawa organik melalui dinding plat silika, diamana senya organik yang dibawa akan meninggalkan jejak yang dapat dilihat pada sinar $\mathrm{UV}_{254}$. Hasil yang diperoleh menunjukan noda kafein hasil ekstraksi sejajar dengan noda kafein baku standar (Gebeyehu \& Bikila, 2015). Jarak Rf antara sampel dengan larutan baku standar tidak beda jauh, artinya sampel yang diteliti mengandung kafein. Rf KLT yang bagus berkisar antara $0,2-0,8$. Jika $R f$ terlalu tinggi, yang harus dilakukan adalah mengurangi kepolaran eluen, dan sebaliknya.

\section{Panjang gelombang serapan maksimum}

Penentuan panjang gelombang serapan maksimum dilakukan dengan menggunakan larutan kafein baku standar pada konsentrasi 20 ppm dan diukur absorbansi dengan panjang gelombang 270nm-300 nm. Spektrofotometri UV-Vis adalah teknik analisis spektroskopik yang memakai sumber REM (radiasi elektromagnetik) ultraviolet dekat (190-380 nm) dan sinar tampak (380-780 nm) dengan memakai instrumen spektrofotometer. Hasil pengukaran ini diperoleh panjang gelombang serapan maksimum pada $285 \mathrm{~nm}$ dengan nilai absorbansi 0,199 . Penetapan panjang gelombang serapan maksimum ini berujuan untuk mendapatkan panjang gelombang yang memberikan serapan terbesar yang selanjutnya digunakan untuk penentuan kurva kalibrasi dan penetapan kadar kafein pada sampel. Hasil pengukuran panjang gelombang serapan maksimum diperoleh $285 \mathrm{~nm}$, ini berbeda dengan literatur yaitu $273 \mathrm{~nm}$ (Fatoni, 2015 dan Aryanu, dkk., 2016). Hal ini dapat dipengaruhi oleh matrik dan penggunaan alat yang berbeda (Nersyanti, 2006).

\section{Kurva kalibrasi dan persamaan garis regresi}

Penentuan linieritas kurva kalibrasi kafein baku standar dengan pelarut aquades dilakukan pada konsentrasi $0,10,20,30$ dan $40 \mathrm{ppm}$ dan diukur pada panjang gelombang serapan maksimum $285 \mathrm{~nm}$. Aquades digunakan sebagai blangko dan didapat hasil seperti terlihat pada Tabel 2 .

Tabel 2. Absorbansi larutan standar kafein berbagai konsentrasi pada panjang gelombang $285 \mathrm{~nm}$.

\begin{tabular}{ccc}
\hline No & Konsentrasi & Absorbansi \\
\hline 1 & 0 & 0,000 \\
2 & 10 & 0,033 \\
3 & 20 & 0,200 \\
4 & 30 & 0,308 \\
5 & 40 & 0,371 \\
\hline
\end{tabular}

Setelah diperoleh hasil pengukuran absorbansi untuk larutan standar kafein maka konsentrasi dialurkan terhadap konsentrasi (ppm) larutan standar kafein untuk mendapatkan kurva kalibrasi berupa garis linear dan didapat persamaan regresi $\mathrm{y}=0.00109 \mathrm{x}-0.0438$ dengan nilai $\mathrm{R}^{2}=0.9771$, kriteria penerimaan koefisien korelasi adalah $\mathrm{R}^{2} \geq 0,95$. Berdasarkan pengukuran, diperoleh data yang tidak, ini dikarenakan adanya faktor yang mempengaruhi hasil pengukuran seperti variasi konsentrasi larutan yang digunakan hanya berdasarkan perhitungan dan tidak dilakukan pengukuran konsentrasi lebih lanjut.

\section{Kadar kafein pada kopi bubuk lokal}

Data hasil pengukuran absorbansi dan hasil perhitungan kadar kafein pada 6 sampel kopi bubuk lokal dapat dilihat pada Tabel 3.

Tabel 3. Absorbansi \& kadar pada berbagai sampel kopi bubuk lokal.

\begin{tabular}{|c|c|c|c|c|c|}
\hline \multirow[t]{2}{*}{ No } & \multirow[t]{2}{*}{ Sampel } & \multirow[t]{2}{*}{$(\mathrm{Y})$} & \multirow[t]{2}{*}{$(\mathrm{X})$} & \multicolumn{2}{|c|}{$\begin{array}{l}\text { Kadar kafein pada } \\
\text { kopi bubuk dalam } \\
1 \text { gram }\end{array}$} \\
\hline & & & & $\mathrm{mg}$ & $\% \mathrm{~b} / \mathrm{b}$ \\
\hline 1 & A & 0,029 & 6,678 & 8,348 & 0,83 \\
\hline 2 & B & 0,136 & 16,495 & 20,619 & 2,06 \\
\hline 3 & $\mathrm{C}$ & 0,096 & 12,825 & 16,032 & 1,60 \\
\hline 4 & $\mathrm{D}$ & 0,186 & 21,082 & 26,353 & 2,63 \\
\hline 5 & $\mathrm{E}$ & 0,065 & 10,394 & 12,993 & 1,29 \\
\hline 6 & $\mathrm{~F}$ & 0,107 & 13,834 & 17,293 & 1,72 \\
\hline
\end{tabular}

Hasil pengukuran diperoleh kadar kafein pada enam sampel kopi bubuk lokal dalam 1 gram berbeda-beda, ini dikarenakan sampel kopi yang digunakan tidak murni atau dan campuran bahan lain. Adanya pencampur akan mempengaruhi rasa, khasiat serta kadar kafein yang terkandung dalam kopi (Putri \& Ulfin, 2015). Faktor lain yang mempengaruhi hasil pengukuran adalah, sampel kopi yang digunakan tidak diperoleh dari satu tempat tumbuh melainkan dari tiga tempat tumbuh yaitu di Buol, Poso dan Sigi. Perbedaan letak geografis dapat mempengaruhi kandungan senyawa pada tanaman karena unsur hara yang terdapat dalam tanah berbeda proporsinya (Farida, dkk., 2013).

\section{Kesimpulan}

Kadar kafein pada enam sampel kopi bubuk lokal dalam 1 gram berturut-turut mempunyai kadar kafein 8,$348 ; 20,619 ; 16,032 ; 26,353 ; 12,993$ dan $17,293 \mathrm{mg}$. jika dibuat dalam \% b/b maka setiap 1 gram kopi bubuk 6 sampel tersebut mengandung berturut-turut 0,$83 ; 2,06 ; 1,60 ; 2,63 ; 1,29$ dan $1,72 \%$ kadar kafein. Enam sampel kopi bubuk lokal, empat diantaranya yaitu sampel A, C, E dan F memenuhi syarat SNI 01-3542-2004 yaitu antara 0,45\%-2\% b/b, sedangkan dua diantaranya yaitu sampel B dan D tidak sesuai, karena melebihi dari 2\% yaitu sebesar $2,06 \%$ dan $2,63 \%$.

\section{Ucapan Terima kasih}

Ucapan terimakasih penulis sampaikan kepada Idha Kesuma Utami selaku laboran laboratorium 
agroteknologi, yang telah memberikan bimbingan dan masukan dalam menyelesaikan penelitian ini.

\section{Referensi}

Ali, M. M., Eisa, M., Taha, M. I., Zakaria, B. A. \& Elbhashir, A. A. (2012). Determination of caffiene in some sudanese bayeragens by high performace liquid chromatography. Asian Network for Scientific Information, 11(4), 336342.

Aptika, N. M. D., Tunas, I. K , \& Sutema, I. A. M. P. (2015). Analisis kadar kafein pada kopi hitam di bukian gianyar menggunakan spektrofotometer UV-Vis. Chemistry Laboratory, 2(1), 30-37.

Arwangga, A. F., Asih I. A. R. A., \& Sudiarta, I. W,. (2016). Analisis kandungan kafein pada kopi di desa sesaot narmada menggunakan spektrofotometri $U V$-Vis. Denpasar: Jurusan Kimia FMIPA Universitas Udayana.

Djajanegara, I. (2009). Pemakaian sel hela dalam uji sitotoksisitas fraksi kloroform dan etanol ekstrak daun annona squamosal. Jurnal Ilmu Kefarmasian Indonesia, 7(1), 7-11.

Farida, A., Ristanti R., \& Kumoro, A. (2013). Penurunan kadar kafein dan asam total pada biji kopi robusta menggunakan teknologi farmasi anaerob fakultatif dengan mikroba nopkor $\mathrm{Mz}-$ 15. Jurnal Teknologi Kimia dan Industri, 2(1), 3037.

Fatoni, A. (2015). Analisa secara kualitatif dan kuantitatif kadar kafein dalam kopi bubuk lokal yang beredar di kota palembang menggunakan spektrofotometer UV-Vis. Palembang: Sekolah Tinggi Ilmu Farmasi Bhakti Pertiwi.

Fernandez-Caceres, P. M. J., Martin, M. P. , \& Gonzalez, A. G. (2001). Differentiation of tea (Camellia sinensis) varieties and their geographical origin according to their metal content. Journal of Agricultural and Food Chemistry, 49(10), 47754779 .
Gebeyehu, B. T., \& Bikila, S. L. B. (2015). Determination of caffeine content and antioxidant activity of coffee. American Journal of Applied Chemistry 3(2), 69-76.

Levita J., Mutakim, \& Hasanah, U. (2004). Identifikasi kadar kafein dalam beberapa produk minuman ringan bersoda jenis cola kemasan kaleng yang beredar di jatinangor dengan metode kromatografi cair kerja tinggi (KCKT). Majalah Ilmu Farmasi Farmaka, 2(4), 122-128.

Ling, L. S., Daud, N. I. N, \& Hassan, O. (2001). Determination of coffe content in coffe mixtures. Malaysian Journal of Analytical Sciences, 7(2), 323-327.

Maramis, R. K., Citraningtyas, G., \& Wehantouw, F. (2013). Analisis kafein dalam kopi bubuk di kota manado menggunakan spektrofotometri UV-Vis. Pharmacom Jurnal Ilmiah Farmasi, 2(4), 122128.

Putri, D. D., \& Ulfin, I. (2015). Pengaruh suhu dan waktu ekstraksi terhadap kadar kafein dalam teh hitam. Jurnal Sains dan Seni ITS, 4(2), $2337-$ 3520.

Rahayu, T., \& Triastuti, R. (2007). Optimasi fermentasi cairan kopi dengan inokulan kultur kombucha (Kombucha coffee). Jurnal Penelitian Science dan Teknologi, 8(1), 15-29.

Sofiana, N. (2011). Fakta tentang kopi. Yogyakarta: Cahaya Atma Pustaka.

Tjay, T. H, \& Rahadja, K. (2007). Obat-obat penting, khasiat penggunaan dan efek-efek sampingnya (Edisi IV). Jakarta: PT Elex Media Komputindo.

Wanyika, H. N., Gatebe, E. G., Gitu, L. M., Ngumba, E. K., \& Maritim, C. W. (2010). Determination of caffeine content of tea and instant coffee brands found in the kenyan market. African Journal of Food Science 4(6), 353358. 